\title{
The relation between the production efficiency of nitrogen atoms and the electrical characteristics of a Dielectric Barrier Discharge
}

\author{
F. J. J. Peeters ${ }^{1,2}$, R. Yang ${ }^{3}$, M. C. M. van de Sanden ${ }^{1,2}$ \\ ${ }^{1}$ Eindhoven University of Technology, Department of Applied Physics, POB 513, NL-5600 MB \\ Eindhoven, The Netherlands \\ ${ }^{2}$ FOM institute DIFFER, P.O. Box 1207, 3430 BE, Nieuwegein, The Netherlands \\ ${ }^{3}$ Peking University, Beijing National Laboratory for Molecular Sciences (BNLMS), College of \\ Chemistry and Molecular Engineering, Beijing 100871, People's Republic of China \\ (e-mail: f.j.j.peeters@differ.nl)
}

\begin{abstract}
In a nitrogen plasma jet, atomic nitrogen is the longest lived radical species and, through recombination, gives rise to highly reactive excited nitrogen species. In this paper, the atomic nitrogen concentration in the effluent of a nitrogen-fed Dielectric Barrier Discharge (DBD) is determined by using direct 2D imaging of the visible FPS emission. The relationship between radical production and the electrical characteristics of the discharge is assessed by making use of an electrical model which assumes only a part of the electrode area is discharged every halfcycle. For the pure nitrogen jet used here, the specific energy input per nitrogen atom is found to be $320 \pm 20 \mathrm{eV} /$ atom, comparable to the specific energy for other atomic nitrogen sources in the literature. It is shown that the production efficiency of atomic nitrogen does not depend on the amplitude of the applied voltage of the DBD and any increase in radical production is due to an increase of the electrode area covered by the discharge, i.e. an increase in the number of microdischarges.
\end{abstract}

\section{Introduction}

The potential of Atmospheric Pressure Plasma Jets (APPJ) for industrial application, such as deposition of thin films, surface modification or surface pre-treatment, is determined by the type and concentration of active species in the jet. In the case of the PlasmaLine ${ }^{\circledR}$ system, a high nitrogen flow between $5-15 \mathrm{~m} / \mathrm{s}$ passes through a DBD to activate the gas. See Figure 1 for a schematic overview of the system and Figure 2 for a photograph of the PlasmaLine ${ }^{\circledR}$ jets. Nitrogen is highly suitable as a carrier gas for large scale processing, since it is much cheaper than noble gases such as argon or helium, has a high propensity for forming metastable excited states via energy-pooling reactions and can be dissociated into nitrogen atoms, providing a highly reactive afterglow. Atomic nitrogen is expected to be the plasma radical with the longest lifetime and the highest concentration in the post-discharge and hence the main reactive particle in the plasma jet [1-4]. Our interest lies with determining the production efficiency of atomic nitrogen as a function of the applied voltage amplitude in the DBD source and evaluate its relationship with the surface coverage $\beta$ of the discharge, introduced by Peeters et al. in [5].

In this paper, the atomic nitrogen concentration at the source exit is quantified by measuring the optical emission in the jet of the $\mathrm{N}_{2}$ First Positive System (FPS), $\mathrm{N}_{2}\left(\mathrm{~B}^{3} \Pi_{\mathrm{g}} \rightarrow \mathrm{A}^{3} \Sigma_{\mathrm{u}}{ }^{+}\right.$), which has an intensity proportional to the rate of recombination of $\mathrm{N}$ atoms because direct electron excitation of $\mathrm{N}_{2}$ is absent. The rate of decay of the FPS emission can then be used to determine $\mathrm{N}$ atom concentrations, provided the gas flow velocity in the jet is known [6]. Quantifying atomic $\mathrm{N}$ in this way is not new; in previous work by other authors, the flowing afterglow, or jet, from a small-scale atmospheric pressure source is directed into a quartz tube, which allows for a large spatial extent of the jet by adjusting flow velocity, while simultaneously preventing 
admixture of the surrounding air [3,7]. Using these tubes, the decay of the FPS emission can be reliably measured using Optical Emission Spectroscopy (OES) at various distances from the plasma source. For the commercial PlasmaLine ${ }^{\circledR}$ system, however, adding a flow tube to the $20 \mathrm{~cm}$ wide plasma jets is impractical and direct 2D CCD imaging of the spatial decay of the FPS emission in the jet is used instead. In the absence of a flow tube, both gas flow velocity and the admixture of molecular oxygen and water from the surrounding air have to be assessed to obtain accurate measures of the atomic $\mathrm{N}$ concentration in the source.

This paper is structured as follows: first, the optical emission from the jet is compared to the emission from the discharge over a wide wavelength range using low resolution $(0.3 \mathrm{~nm})$ spectroscopy. From this analysis it is concluded that the FPS emission in the jet depends solely on the recombination of $\mathrm{N}$ atoms and can be used to quantify its concentration. This emission is then measured as a function of position using an iCCD camera, with flow velocity measurements using a hot-wire anemometer providing the relationship between position and time-of-flight of species in the jet [8]. Combining this data, the atomic $\mathrm{N}$ concentration at the source exit is determined as a function of applied voltage amplitude. Also, an estimate of the admixture of molecular oxygen and water is made using a 1D convection-reaction model, so that their influence on the atomic $\mathrm{N}$ measurements can be assessed. Finally, the atomic $\mathrm{N}$ production is compared to values from literature and related to the results of the electrical model of the DBD presented in [5].

\section{Experimental setup}

The PlasmaLine ${ }^{\circledR}$ source was already described in [5]. Very high dissipated power densities between 60 and $100 \mathrm{~W} / \mathrm{cm}^{3}$ are reached in the discharge, as determined from $Q-V$ diagrams, with the maximum discharge volume of $6 \mathrm{~cm}^{3}$ corrected by the fractional surface coverage $\beta$; see [5] for details. The nitrogen discharge itself is sealed off from the atmosphere by virtue of the large gas flow, while the plasma jets emerging from the DBDs are exposed to the surrounding air. The $\mathrm{N}_{2}$ process gas is $99.999 \%$ pure, with contributions of $<3 \mathrm{ppm} \mathrm{O}_{2}$ and $<$ $2 \mathrm{ppm} \mathrm{H}_{2} \mathrm{O}$ (Air Products Nitrogen Premier). A schematic of the plasma source is shown in Figure 1. The setup is placed inside a ventilation cabinet with an exhaust flow of $5 \mathrm{~m}^{3} \mathrm{~s}^{-1}$. The relative humidity $\mathrm{RH}$ of the ambient air in the lab is $\sim 50 \%$ at a temperature of $20^{\circ} \mathrm{C}$.

Spectra of the discharge between 200 and $850 \mathrm{~nm}$ are obtained using an ANDOR Shamrock SR-303i spectrograph with a 150 lines/mm grating and $500 \mathrm{~nm}$ blaze combined with an ANDOR iStar DH734-18-03 intensified CCD camera through a fiber optic cable with an $18^{\circ}$ collection angle a distance of $10 \mathrm{~cm}$ from a discharge slit. This is depicted schematically in Figure 1, optical setup (I). Exposure times for these measurements are $50 \mathrm{~ms}$ for $300-500 \mathrm{~nm}$ and $10 \mathrm{~s}$ from $500-850 \mathrm{~nm}$ with maximum intensifier gain. Since the brightness of the discharge is very high, no collection optics are needed to obtain qualitative spectra. To obtain spectra of the jet, or flowing afterglow, a higher sensitivity is needed. In dark conditions, the afterglow is barely visible to the naked eye as a $5 \mathrm{~mm}$ long plasma jet. To characterize the emission, two plano-convex lenses with a focal length of $30 \mathrm{~cm}$ and an aperture size of $2 \mathrm{~mm}$ are used to image the side of a single jet onto an optical fiber, see Figure 1, optical setup (II). Exposure times of $0.4 \mathrm{~s}$ and 300 accumulations at the maximum intensifier gain are required to obtain the spectra. The focal point of this setup is located approximately halfway along the length of the jet and $1 \mathrm{~mm}$ from the source exit. The optical path is covered to block any ambient stray light or direct and reflected light from the discharge. Because the imaged area is $1 \mathrm{~mm}$ wide, the spectra represent the averaged emission over what is likely a wide range of 
species densities, therefore no absolute calibration of the spectra is attempted. For all spectra the wavelength range of $200-850 \mathrm{~nm}$ is achieved in four separate measurements $(180-400$ $\mathrm{nm}, 400-500 \mathrm{~nm}, 500-700 \mathrm{~nm}$ and $700-850 \mathrm{~nm}$ ) and appropriate filters are used for each measurement to prevent higher order diffraction peaks. The quantum efficiency of the iCCD is effectively zero from $900 \mathrm{~nm}$ and above, so no spectra are obtained in this wavelength region. The position of the fiber in optical setup (I) was chosen such that the optical collection volume for this measurement was approximately equal to that of optical setup (II); $\sim 0.1 \mathrm{~cm}^{3}$ in both cases. Direct 2D imaging of the jet is carried out using the same ANDOR iStar iCCD camera in combination with a Tamron 70-300 mm Macro lens. The camera is aligned parallel to the source exit using an alignment laser in combination with position markers; see Figure 1, optical setup (III). An optical filter is used to block any emission below a wavelength of $450 \mathrm{~nm}$. The exposure time is set at $0.5 \mathrm{~s}$, with 500 accumulations at the maximum intensifier gain of 255 . The resulting image has a resolution of 400 pixels $/ \mathrm{cm}$, with the jet being imaged onto the 13.3 x $13.3 \mathrm{~mm}$ CCD at approximately 1:2.

For analysis of the 2D jet images, a custom-built Hot-Wire (HW) anemometer flow sensor is used to determine both the effective width of the plasma jet and the gas flow velocity between 0 and $6 \mathrm{~mm}$ from the source exit. The device is calibrated using a well-defined flow. The flow data is used to calculate the time-of-flight of particles as a function of distance to the source exit. Both the flow sensor and the calculation of time-of-flight are treated in more detail in the supplementary data to this article.

\section{Results}

\subsection{Qualitative analysis of spectra}

Typical optical emission spectra for the discharge and jet are depicted in Figure 3. At all applied voltage amplitudes $(8.4$ to $11.6 \mathrm{kV})$ the spectra are qualitatively equivalent. The spectra show contributions from the NO $\gamma$ system, $\mathrm{NO}\left(\mathrm{A}^{2} \Sigma^{+} \rightarrow \mathrm{X}^{2} \Pi\right)$, NO $\beta$ system, $\mathrm{NO}\left(\mathrm{B}^{2} \Pi \rightarrow \mathrm{X}^{2} \Pi\right)$, First Negative System (FNS), $\mathrm{N}_{2}{ }^{+}\left(\mathrm{B}^{2} \Sigma_{\mathrm{u}}{ }^{+} \rightarrow \mathrm{X}^{2} \Sigma_{\mathrm{g}}{ }^{+}\right.$), Second Positive System (SPS), $\mathrm{N}_{2}\left(\mathrm{C}^{3} \Pi_{\mathrm{u}}\right.$ $\rightarrow \mathrm{B}^{3} \Pi_{\mathrm{g}}$ ), First Positive System (FPS), $\mathrm{N}_{2}\left(\mathrm{~B}^{3} \Pi_{\mathrm{g}} \rightarrow \mathrm{A}^{3} \Sigma_{\mathrm{u}}{ }^{+}\right.$) and the Herman Infra-red system (HIR), $\mathrm{N}_{2}\left(\mathrm{C}^{\prime \prime} \Pi_{\mathrm{u}} \rightarrow \mathrm{A}^{\prime}{ }^{5} \Sigma_{\mathrm{g}}{ }^{+}\right)[9,10]$. No emission from water-related species, such as the $\mathrm{OH}(\mathrm{A}$ $\left.{ }^{2} \Sigma^{+} \rightarrow \mathrm{X}^{2} \Pi\right)$ transition expected at $306 \mathrm{~nm}$, is evident from these spectra [10]. All excited states will hereafter be referred to as $\mathrm{NO}(\mathrm{A}), \mathrm{NO}(\mathrm{B}), \mathrm{N}_{2}(\mathrm{~A}), \mathrm{N}_{2}(\mathrm{~B}), \mathrm{N}_{2}(\mathrm{C})$ and $\mathrm{N}_{2}\left(C^{\prime \prime}\right)$.

The bulk of the SPS and FPS emission observed in the discharge spectrum is the direct result of electron excitation processes, while HIR is exclusively the result of $\mathrm{N}_{2}\left(\mathrm{C}^{\prime \prime}\right)$ production via energy-pooling reactions of $\mathrm{N}_{2}(\mathrm{~A})$ metastables in the post-discharge phase [11-15]:

$$
\mathrm{N}_{2}(\mathrm{~A})+\mathrm{N}_{2}(\mathrm{~A}) \rightarrow \mathrm{N}_{2}\left(C^{\prime \prime}, \mathrm{C}, \mathrm{B}\right)+\mathrm{N}_{2} .
$$

The spectrum of the jet is also depicted in Figure 3 and is very similar to the spectrum reported by Ricard et al. obtained from an $\mathrm{N}_{2}$ afterglow at roughly the same distance from the source in terms of time-of-flight of the active species ( $<1 \mathrm{~ms}$ from source exit) [7]. The FPS emission lines between 500 and $650 \mathrm{~nm}$ indicate the presence of highly vibrationally excited $\mathrm{N}_{2}\left(\mathrm{~B}, \mathrm{v}^{\prime} \geq\right.$ 10). This is a clear signature of ground-state atomic nitrogen recombination in the late, or Lewis-Rayleigh afterglow via the reaction [6]: 


$$
\begin{aligned}
& \mathrm{N}+\mathrm{N}+\mathrm{M} \rightarrow \mathrm{N}_{2}(\mathrm{X}, \mathrm{A}, \mathrm{B})+\mathrm{M} \\
& \mathrm{N}_{2}(\mathrm{~B}) \rightarrow \mathrm{N}_{2}(\mathrm{~A})+h v(\mathrm{FPS})
\end{aligned}
$$

where $\mathrm{M}$ is a third particle, either $\mathrm{N}_{2}$ or $\mathrm{O}_{2}$. Reaction $\mathrm{R} 2$ will lead to overpopulation of the $\mathrm{N}_{2}\left(\mathrm{~B}, \mathrm{v}^{\prime}=11\right)$ state, as is clearly observed in Figure 3(b) at around $540 \mathrm{~nm}, 580 \mathrm{~nm}$ and 625 $\mathrm{nm}$ [16]. In a Lewis-Rayleigh afterglow the excited $\mathrm{N}_{2}$ species are created without any significant contribution of the metastable $\mathrm{N}_{2}(\mathrm{~A})$ energy pooling reaction $\mathrm{R} 1$, so that, contrary to the discharge spectrum, reaction R2 is the sole source of FPS emission [17]. Even within 1 $\mathrm{mm}$ of the source exit, the contribution of the energy pooling reaction $\mathrm{R} 1$ is negligible, which will be tested further below.

\subsection{Quantitative analysis}

Since we can conclude from the spectrum of the jet in Figure 3 that the plasma is in the late afterglow phase within $1 \mathrm{~mm}$ of the source exit, the emission intensity above wavelengths of $500 \mathrm{~nm}, I_{F P S}$, can be used to quantify the atomic nitrogen concentration, via the concentration of $\mathrm{N}_{2}(\mathrm{~B})$ :

$$
I_{F P S}(t)=k_{R 3}\left[\mathrm{~N}_{2}(\mathrm{~B})\right](t),
$$

with $k_{R 3}$ the Einstein coefficient for spontaneous emission of reaction R3. The creation of $\mathrm{N}_{2}(\mathrm{~B})$ is the result of recombination of atomic $\mathrm{N}$, via reaction $\mathrm{R} 2$. The concentration of atomic $\mathrm{N}$ will decay according to the differential equation:

$$
\frac{\partial[\mathrm{N}](t)}{\partial t}=-2 k_{R 2}[\mathrm{M}]([\mathrm{N}](t))^{2}
$$

Note that we assume here that $\mathrm{O}_{2}$ and $\mathrm{H}_{2} \mathrm{O}$ and, hence, NO concentrations are sufficiently low that additional loss channels for atomic $\mathrm{N}$ need not be considered. This assumption will be tested at a later point, using a 1D convection-reaction model. Solving (1) gives:

$$
[\mathrm{N}](t)=\frac{[\mathrm{N}]_{\text {source }}}{1+2 k_{R 2}[\mathrm{M}][\mathrm{N}]_{\text {source }} t},
$$

where $[\mathrm{N}]_{\text {source }}$ is the atomic nitrogen concentration at the source exit. For an accurate determination of [N] source it is critical to know the value of $k_{R 2}$, which determines the total loss rate of atomic $\mathrm{N}$. A value on the order of $4 \cdot 10^{-33} \mathrm{~cm}^{6} \mathrm{~s}^{-1}$ at $300 \mathrm{~K}$ for $k_{R 2}$ is often cited, where $[\mathrm{M}]=\left[\mathrm{N}_{2}\right]$, which leads to underestimation of the decay rate of atomic $\mathrm{N}$ [3,18-20]. A literature study reveals that an average value on the order of $1.5 \cdot 10^{-32} \mathrm{~cm}^{6} \mathrm{~s}^{-1}$ can be assumed, based on direct measurement techniques such as NO titration and ESR [21-26]. Less than 1 in 6 recombinations of atomic $\mathrm{N}$ lead to an $\mathrm{N}_{2}$ (B) state [20], though this ratio has no effect on the results presented here, only on the absolute intensity of the FPS emission.

Aside from reactions $\mathrm{R} 2$ and $\mathrm{R} 3$, the concentration of $\mathrm{N}_{2}(\mathrm{~B})$ is reduced by quenching reactions, of which the following is the most relevant under our conditions [19]:

$$
\mathrm{N}_{2}(\mathrm{~B})+\mathrm{N}_{2} \rightarrow \mathrm{N}_{2}(\mathrm{~A})+\mathrm{N}_{2}
$$


The rate coefficient of $\mathrm{R} 4$ for highly vibrationally excited $\mathrm{N}_{2}\left(\mathrm{~B}, \mathrm{v}^{\prime} \geq 10\right)$ is approximately $3 \cdot 10^{-}$ ${ }^{11} \mathrm{~cm}^{3} \mathrm{~s}^{-1}[14,27]$. This reaction will far outweigh the loss rate due to spontaneous emission via reaction $\mathrm{R} 3$, at $10^{5} \mathrm{~s}^{-1}$. Quenching of $\mathrm{N}_{2}$ (B) by oxygen- and hydrogen-containing species can be similarly neglected if the $\mathrm{O}_{2}$ content is $<<10 \%$. As we will show below, these conditions are met for the emission data. Reaction $\mathrm{R} 4$ with an $\mathrm{N}_{2}$ concentration of $2.7 \cdot 10^{19} \mathrm{~cm}^{-3}$ predicts a 1/e decay time for $\mathrm{N}_{2}$ (B) of $\sim 1 \mathrm{~ns}$. At a flow rate on the order of $5 \mathrm{~m} / \mathrm{s}$, this leads to only a few tens of nanometers of displacement between creation and destruction. We can, therefore, use a steady-state approximation for the $\mathrm{N}_{2}(\mathrm{~B})$ concentration at any point in the plasma jet. Via reaction $\mathrm{R} 2$ and (3), the relation between $I_{F P S},\left[\mathrm{~N}_{2}(\mathrm{~B})\right]$ and $[\mathrm{N}]$ is then simply:

$$
\frac{1}{\sqrt{I_{F P S}(t)}} \propto \frac{1}{\sqrt{\left[\mathrm{N}_{2}(\mathrm{~B})\right](t)}} \propto \frac{1}{[\mathrm{~N}](t)} \propto\left(1+2 k_{R 2}\left[\mathrm{~N}_{2}\right][\mathrm{N}]_{\text {source }} t\right) .
$$

For simplicity, we assume the only third particle is $\mathrm{N}_{2}$ [20]. Equation (4) shows that the decay of $\left(I_{F P S}\right)^{-1 / 2}$ with time-of-flight from the source exit is a direct measure of $[\mathrm{N}]_{\text {source }}$.

An example of $I_{F P S}$, imaged using the iCCD camera with a macrolens (Figure 1, optical setup (III)), is shown in Figure 4. The spatial resolution is 40 pixels $/ \mathrm{mm}$. The conversion of this data to plots of $\left(I_{F P S}\right)^{-1 / 2}$ as a function of time-of-flight in the jet, by making use of flow sensor measurements, is treated in the supplementary data to this article. The final results for three applied voltage amplitudes are depicted in Figure 5. The $I_{F P S}(t)$ can only be determined up to $\sim 4.5 \mathrm{~mm}(0.8 \mathrm{~ms})$ from the source, as the emission intensity drops below the detection limit at this point.

Since the initial slope of $\left(I_{F P S}\right)^{-1 / 2}$ in Figure 5 is indeed constant, and assuming the initial $\mathrm{O}_{2}$ and $\mathrm{H}_{2} \mathrm{O}$ concentrations in the process gas (at $3 \mathrm{ppm}$ and $2 \mathrm{ppm}$, respectively) are negligible, this slope is a direct measure of the atomic $\mathrm{N}$ concentration in the source, $[\mathrm{N}]_{\text {source }}$, via (4). The results are depicted in Figure 6 for a wide range of applied voltage amplitudes. The error bars in $[\mathrm{N}]_{\text {source }}$ are due to the uncertainty in gas flow velocity and the fitting error of the initial slope, but do not include the systematic inaccuracy in recombination rate constant $k_{R 2}$. Using $k_{R 2}=4 \cdot 10^{-33} \mathrm{~cm}^{6} \mathrm{~s}^{-1}$, instead of $k_{R 2}=1.5 \cdot 10^{-32} \mathrm{~cm}^{6} \mathrm{~s}^{-1}$ in (4), would result in atomic $\mathrm{N}$ concentrations nearly four times higher, on the order of $10^{16} \mathrm{~cm}^{-3}$. The specific energy input per produced $\mathrm{N}$ atom would also be proportionally lower, however, and much less than values reported in the literature for similar sources, as discussed below. The degree of dissociation of $\mathrm{N}_{2}$ is, at any rate, less than $10^{-3}$ based on this data, so that depletion of $\mathrm{N}_{2}$ does not need to be considered in our analysis.

\subsection{Chemical kinetic model}

To verify whether energy pooling from $\mathrm{N}_{2}(\mathrm{~A})$, and chemical reactivity from admixture of $\mathrm{O}_{2}$ and $\mathrm{H}_{2} \mathrm{O}$ can be truly neglected in the above analysis, a $1 \mathrm{D}$ convection-reaction model containing 380 chemical reactions and 59 species is used. It is assumed that the decay of the emission on the center streamline of the jet can be described by solving a 1D chemical kinetic model over time, neglecting diffusion of species away from the center streamline. For each species the governing continuity equation is given by:

$$
\frac{\partial n(t)}{\partial t}=\sum_{i} k_{i} \prod_{j} n_{j, i}(t)+S_{n}(t) .
$$


In this equation $t$ is time-of-flight, $n(t)$ the concentration of the species under consideration in units of $\mathrm{cm}^{-3}, k_{i}$ a reaction rate coefficients leading to either creation or destruction of species $n$ in units of $\mathrm{s}^{-1}, \mathrm{~cm}^{3} \mathrm{~s}^{-1}$ or $\mathrm{cm}^{6} \mathrm{~s}^{-1}$, depending on the order of the reaction, $n_{j, i}(t)$ the concentration of species $j$ involved in reaction $i$ and $S_{n}(t)$ a time-dependent source term for species $n$ in units of $\mathrm{cm}^{-3} \mathrm{~s}^{-1}$, used where applicable. Equation (5) is solved for 59 species, which are listed in Table 1 . The 380 reactions and rate coefficients are provided as supplementary data in the online version of this article. A constant gas temperature of $320 \mathrm{~K}$ is assumed throughout the streamline. Electrons are assumed to be cold, with $T_{e}=0.1 \mathrm{eV}$, so that electron impact reactions can be neglected. The initial concentration of $\mathrm{N}_{2}(\mathrm{~A})$ in the discharge is taken from literature values for $\mathrm{N}_{2}$ DBDs and is $10^{14}-10^{15} \mathrm{~cm}^{-3}$ [28-31]. As can be seen in the schematic of Figure 1 , the electrodes of the DBD do not extend towards the source exit but are receded by at least $1 \mathrm{~mm}$. In terms of time-of-flight, $\left[\mathrm{N}_{2}(\mathrm{~A})\right]$ has been decaying for at least $0.2 \mathrm{~ms}$ before the starting point of the jet measurements. The initial conditions for the modeled species are therefore set at $t=-0.2 \mathrm{~ms}$, as listed in Table 1. The increased admixture of $\mathrm{O}_{2}$ and $\mathrm{H}_{2} \mathrm{O}$ for $t$ $>0$ is taken into account by including suitable source terms $S_{\mathrm{O}_{2}}$ and $S_{\mathrm{H}_{2} \mathrm{O}}$ for both these species. A relative proportion $S_{\mathrm{H}_{2} \mathrm{O}} / S_{\mathrm{O}_{2}} \approx 0.074$ is assumed, corresponding to the conditions of the ambient air in the lab, with $\mathrm{RH} \approx 50 \%$ at $20^{\circ} \mathrm{C}$. The source term $S_{\mathrm{O}_{2}}$ is the time-derivative of the generalized logistic function, which gives a shape of the $\mathrm{O}_{2}$ and $\mathrm{H}_{2} \mathrm{O}$ uptake similar to the uptake of $\mathrm{O}_{2}$ measured by Ellerweg et al. for a He plasma jet in ambient air [32]:

$$
S_{\mathrm{O}_{2}}(t)=\frac{\partial}{\partial t}\left(\frac{\left[\mathrm{O}_{2}\right]_{\max }}{1+(\tau / t)^{a}}\right),
$$

where $\left[\mathrm{O}_{2}\right]_{\max }$ is always set to the ambient level of $21 \% \mathrm{O}_{2}$, or $5.2 \cdot 10^{18} \mathrm{~cm}^{-3}$. The time constant $\tau$ and the exponent $a$, along with $[\mathrm{N}]_{\text {source }}$, are the three fitting parameters in the model. Best fits to the $\mathrm{N}_{2}(\mathrm{~B})$ concentration are obtained for $\tau \approx 6.7 \mathrm{~ms}$ and $a \approx 2.3$ and $[\mathrm{N}]_{\text {source }}$ only $3 \%$ lower than determined in the previous section.

A fit of $\left[\mathrm{N}_{2}(\mathrm{~B})\right]^{-1 / 2}$ to $\left(I_{F P S}\right)^{-1 / 2}$ is depicted in Figure 7 , as well as the obtained $\mathrm{O}_{2}$ and $\mathrm{H}_{2} \mathrm{O}$ concentrations. The $\mathrm{O}_{2}$ and $\mathrm{H}_{2} \mathrm{O}$ admixture remains well below $1 \%$ and, including energy pooling of $\mathrm{N}_{2}(\mathrm{~A})$, leads to no more than a $3 \%$ overestimation of $[\mathrm{N}]_{\text {source }}$ in Figure 6 , which is within the measurement error. Calculated ground state species concentrations for an applied voltage amplitude of $10.1 \mathrm{kV}$ between $t=0$ and $1 \mathrm{~ms}$ are depicted in Figure 8 . The initial concentration of electrons and ions, as well as the initial and final concentration of $\mathrm{H}_{2} \mathrm{O}$, have no appreciable effect on the $\mathrm{N}_{2}$ (B) concentration. The main effect of the admixture of $\mathrm{O}_{2}$ on $\mathrm{N}_{2}$ (B) occurs via the formation of $\mathrm{O}$ and $\mathrm{NO}$, which scavenge $\mathrm{N}$ atoms via the reactions $[19,20,33]$ :

$$
\begin{aligned}
& \mathrm{N}+\mathrm{NO} \rightarrow \mathrm{N}_{2}+\mathrm{O} \\
& \mathrm{N}+\mathrm{O}+\mathrm{M} \rightarrow \mathrm{NO}(\mathrm{X}, \mathrm{B})+\mathrm{M}, \mathrm{M}=\mathrm{N}_{2}, \mathrm{O}_{2} .
\end{aligned}
$$

The effect of $\mathrm{N}_{2}(\mathrm{~A})$ is limited to increased dissociation of $\mathrm{O}_{2}$ via the reaction [19]:

$$
\mathrm{N}_{2}(\mathrm{~A})+\mathrm{O}_{2} \rightarrow \mathrm{N}_{2}+2 \mathrm{O}
$$

and only slightly enhances $\mathrm{N}_{2}(\mathrm{~B})$ concentrations through the energy pooling reaction $\mathrm{R} 1$. 


\section{Discussion}

To evaluate $[\mathrm{N}]_{\text {source }}$, obtained using $2 \mathrm{D}$ imaging, a comparison is made to published data on atomic $\mathrm{N}$ concentrations from various atmospheric pressure plasma sources obtained using conventional techniques, such as NO titration, absolute optical emission, or TALIF. This data is summarized in Table 2, where only the results for maximum $[\mathrm{N}]_{\text {source }}$ are included. Though our values for $[\mathrm{N}]_{\text {source }}$ are significantly higher than those of other DBD sources, they are well below those obtained using microwave plasma on $\mathrm{Ar}-\mathrm{N}_{2}$ mixtures [34]. With respect to the DBD sources in [1,2] and [18], these have estimated dissipated power densities of $8 \mathrm{~W} / \mathrm{cm}^{3}$ and $2 \mathrm{~W} / \mathrm{cm}^{3}$, respectively, while the PlasmaLine ${ }^{\circledR}$ source achieves $90 \mathrm{~W} / \mathrm{cm}^{3}$. Furthermore, the DBD geometry in [1,2] is cylindrical, but with a gap width of $1 \mathrm{~mm}$, twice the minimum gap width of the PlasmaLine ${ }^{\circledR}$, while the DBD in [18] has a planar geometry with a gap width of $2 \mathrm{~mm}$. It seems plausible that DBD geometry can affect $\mathrm{N}$ concentration, even if only through a reduction of the dissipated power per volume of gas. In light of the above comparison, the absolute values of $[\mathrm{N}]_{\text {source }}$ obtained using the $2 \mathrm{D}$ imaging technique appear reasonable, though we are mainly interested in the production efficiency of atomic $\mathrm{N}$, not its absolute value.

To determine the production efficiency of atomic $\mathrm{N}$ in the DBD source, the specific energy input per $\mathrm{N}$ atom, $E_{\mathrm{N}}$, is calculated using

$$
E_{N}=\frac{P}{\beta \Phi[\mathrm{N}]_{\text {source }}},
$$

where $P$ is the input power in the system in $\mathrm{W}, \Phi$ is the gas flow rate through the system in $\operatorname{slm}, \beta$ the surface coverage of the discharge as determined in [5], and $[\mathrm{N}]_{\text {source }}$ the steady-state atomic $\mathrm{N}$ concentration in the source, depicted in Figure 6 . Note that the ratio of power $P$ to the product of surface coverage and gas flow, $\beta \Phi$, is a measure of the energy-input per volume of gas and effectively takes into account the residence time of particles in the discharge. Values of $E_{\mathrm{N}}$ are included for all cases in Table 2, but it is assumed that $\beta=1$, since no information regarding the surface coverage is provided in the cited publications. It can be seen that $E_{N}$ is on the order of $300-500 \mathrm{eV} /$ atom, irrespective of the type of source or gas composition, though the DBD in Townsend mode is less efficient at $800 \mathrm{eV} /$ atom [18]. It can be concluded that the atomic $\mathrm{N}$ production efficiency measured here falls within the expected range. A theoretical value of $(240 \pm 30)$ eV/atom was determined by Tsyganov et al. using a zero-dimensional chemical kinetic model of a uniform discharge in $\mathrm{N}_{2}$ at atmospheric pressure [35]. This model assumes E-fields of $<35 \mathrm{kV} / \mathrm{cm}$, based on gap voltage divided by gap width, and neglects the much higher transient E-fields which locally occur in filamentary microdischarges. The correspondence with the experimental values presented here is quite striking, however, which suggests that such simplifications can be made in chemical kinetic models of filamentary DBDs.

For variable $\beta$, the results of (6) are depicted in Figure 9. While there is a clear increase in $[\mathrm{N}]_{\text {source }}$ with increasing applied voltage amplitude, as depicted in Figure 6 , the specific energy $E_{\mathrm{N}}$ is nearly constant. In other words, the increase in $[\mathrm{N}]_{\text {source }}$ can be accounted for solely by an increase in the areal extent of the discharge, while the discharge itself, or the individual microdischarges it is composed of, remain unchanged. This is consistent with the results of [5], where it is shown that the burning voltage $U_{b}$ of the discharge remains constant, independent of the applied voltage amplitude. The burning voltages $U_{b}$, obtained for the conditions used in 
this work, are also plotted in Figure 9. Since the burning voltage $U_{b}$ is directly related to the reduced electric field, which determines the electron energy distribution function (EEDF) [36,37], it can be expected to determine the dissociation efficiency of $\mathrm{N}_{2}$ for individual microdischarges. A similar independence of production efficiency on applied voltage has been observed for both $\mathrm{O}_{3}$ generation [38] and $\mathrm{CO}_{2}$ dissociation [39] in DBDs.

\section{Conclusions}

It has been shown that direct 2D imaging of the FPS emission in a nitrogen atmospheric pressure plasma jet can be used to obtain atomic $\mathrm{N}$ concentrations in the source, $[\mathrm{N}]_{\text {source }}$. An upper limit on the admixture of surrounding air in the jet can also be determined, where in the first $1 \mathrm{~mm}$ from the source $\mathrm{O}_{2}$ and $\mathrm{H}_{2} \mathrm{O}$ do not significantly affect the FPS emission. The obtained values of $[\mathrm{N}]_{\text {source }}$ are in reasonable agreement with those obtained in other atmospheric pressure plasma sources using conventional techniques.

For the pure nitrogen jet used here, the specific energy input per nitrogen atom is found to be $(320 \pm 20) \mathrm{eV} /$ atom, close to the theoretical minimum and comparable to the specific energy for other atomic nitrogen sources in the literature. More importantly, we observe that the specific energy does not depend on applied voltage amplitude. This is consistent with the electrical model presented in [5], where the burning voltage $U_{b}$ remains constant as a function of applied voltage and only the surface coverage of the discharge increases. It is concluded that radical production is entirely determined by the density of microdischarges on the electrode surface, while individual microdischarges do not change significantly with voltage.

\section{Acknowledgements}

This work was funded by the European Union's FP7 NMP project 'PlasmaNice'. The authors of this work thank R Dams, R Rego and E van Hoof of the Flemish Institute for Technological Research (VITO) for their technical support.

\section{Supplementary data}

Supplementary data associated with this article can be found in the online version, at [address].

\section{References}

[1] Panousis E, Merbahi N, Clément F, Ricard A, Yousfi M, Papageorghiou L, Loiseau JF, Eichwald O, Held B and Spyrou N 2009 Atmospheric Pressure Dielectric Barrier Discharges Under Unipolar and Bipolar HV Excitation in View of Chemical Reactivity in Afterglow Conditions IEEE Trans. Plasma Sci. 37 1004-15

[2] Clément F, Panousis E, Ricard A, Lecoq E, Loiseau J-F and Held B 2010 Study of Dielectric Barrier Discharges in nitrogen and afterglows at atmospheric pressure $J$. Phys. Conf. Ser. 207012007

[3] Panousis E, Ricard A, Loiseau J-F, Clément F and Held B 2009 Estimation of densities of active species in an atmospheric pressure N2 DBD flowing afterglow using optical emission spectroscopy and analytical calculations J. Phys. D. Appl. Phys. 42205201 
[4] Pointu A-M, Ricard A, Dodet B, Odic E, Larbre J and Ganciu M 2005 Production of active species in $\mathrm{N} 2-\mathrm{O} 2$ flowing post-discharges at atmospheric pressure for sterilization J. Phys. D. Appl. Phys. 38 1905-9

[5] Peeters F J J and van de Sanden M C M 2015 The influence of partial surface discharging on the electrical characterization of DBDs Plasma Sources Sci. Technol. 24015016

[6] Bockel S, Diamy a. M and Ricard A 1995 Optical diagnostics of active species in N2 microwave flowing post-discharges Surf. Coatings Technol. 74-75 474-8

[7] Ricard A, Panousis E, Clément F, Sindzingre T and Loiseau J-F 2008 Production of active species in a N2 DBD plasma afterglow Eur. Phys. J. Appl. Phys. 42 63-6

[8] McKeon B, Comte-Bellot G, Foss J, Westerweel J, Scarano F, Tropea C, James M, Lee J, Cavone A, Schodl R, Koochesfahani M, Andreopoulos Y, Dahm W, Mullin J, Wallace J, Vukoslavčević P, Morris S, Pardyjak E and Cuerva A 2007 Velocity, Vorticity, and Mach Numer Springer Handbook of Experimental Fluid Mechanics pp $215-471$

[9] Pearse R W B and Gaydon A G 1984 The Identification of Molecular Spectra

[10] Šimek M, Babický V, Clupek M and Sunka P 2001 Observation of the N2 Herman infrared system in pulsed positive streamer J. Phys. D. Appl. Phys. 34 3185-90

[11] Hays G N 1973 Population of N2(B) by N2(A) during the nitrogen afterglow J. Chem. Phys. 591507

[12] Hays G N 1973 Reaction rate constant for $2 \mathrm{~N} 2(\mathrm{~A}) \rightarrow \mathrm{N} 2(\mathrm{C})+\mathrm{N} 2\left(\mathrm{X}, v^{\prime}>0\right) \mathrm{J}$. Chem. Phys. 596088

[13] Hays G N, Tracy C J, Demonchy A R and Oskam H J 2000 Production of N2(C) and N2(C') by Mutual Collisions of N2(A) Metastable Molecules Chem. Phys. Lett. 14 1-4

[14] Piper L G 1988 State-to-state N2(A3 $\left.\sum+u\right)$ energy pooling reactions. II. The formation and quenching of N2(B3חg, v'=1-12) J. Chem. Phys. 886911

[15] Piper L G 1988 State-to-state N2(A3 $\Sigma+u)$ energy-pooling reactions. I. The formation of N2(C3חu) and the Herman infrared system J. Chem. Phys. 88231

[16] Boudam M K, Saoudi B, Moisan M and Ricard A 2007 Characterization of the flowing afterglows of an $\mathrm{N} 2-\mathrm{O} 2$ reduced-pressure discharge: setting the operating conditions to achieve a dominant late afterglow and correlating the NO $\beta$ UV intensity variation with the $\mathrm{N}$ and $\mathrm{O}$ atom densities J. Phys. D. Appl. Phys. 40 1694-711

[17] Gordiets B F and Ricard A 1993 Production of N, O and NO in N2-O2 flowing discharges Plasma Sources Sci. Technol. 2 158-63

[18] Es-Sebbar E-T, Sarra-Bournet C, Naudé N, Massines F and Gherardi N 2009 Absolute nitrogen atom density measurements by two-photon laser-induced fluorescence 
spectroscopy in atmospheric pressure dielectric barrier discharges of pure nitrogen $J$. Appl. Phys. 106073302

[19] Kossyi I A, Yu Kostinsky A, Matveyev A A and Silakov V P 1992 Kinetic scheme of the non-equilibrium discharge in nitrogen-oxygen mixtures Plasma Sources Sci.

Technol. 1 207-20

[20] Capitelli M A, Ferreira C M, Gordiets B F and Osipov A I 2000 Plasma Kinetics in Atmospheric Gases

[21] Harteck P, Reeves R R and Mannella G 1958 Rate of Recombination of Nitrogen Atoms J. Chem. Phys. 29608

[22] Herron J T, Franklin J L, Bradt P and Dibeler V H 1959 Kinetics of Nitrogen Atom Recombination J. Chem. Phys. 30879

[23] Herron J T, Franklin J L, Bradt P and Dibeler V H 1958 Kinetics of Nitrogen Atom Recombination J. Chem. Phys. 29230

[24] Marshall T C 1962 Studies of Atomic Recombination of Nitrogen, Hydrogen, and Oxygen by Paramagnetic Resonance Phys. Fluids 5743

[25] Clyne M A A and Stedman D H 1967 Rate of Recombination of Nitrogen Atoms $J$. Phys. Chem. 71 3071-3

[26] Miyazaki S and Takahashi S 1967 Reactions of Nitrogen Atom with Methane and with Ethylene Bull. Chem. Soc. Jpn. 41 1456-8

[27] Ricard A, Tétreault J and Hubert J 1991 Nitrogen atom recombination in high pressure Ar-N2 flowing post-discharges J. Phys. B At. Mol. Opt. Phys. 24 1115-23

[28] Panousis E, Merbahi N, Clément F, Yousfi M and Loiseau J-F 2009 Analysis of Dielectric Barrier Discharges under Unipolar and Bipolar Pulsed Excitation IEEE Trans. Dielectr. Electr. Insul. 16 734-41

[29] Stancu G D, Janda M, Kaddouri F, Lacoste D A and Laux C O 2010 Time-Resolved CRDS Measurements of the N 2 ( A $3 \Sigma \mathrm{u}$ ) Density Produced by Nanosecond J. Phys. Chem. A 114 201-8

[30] Šimek M 2003 Determination of N2(A) metastable density produced by nitrogen streamers at atmospheric pressure : 1 . Design of diagnostic method Plasma Sources Sci. Technol. 12 421-31

[31] Šimek M 2003 Determination of N2(A) metastable density produced by nitrogen streamers at atmospheric pressure : 2 . Experimental verification Plasma Sources Sci. Technol. 12 454-63

[32] Ellerweg D, von Keudell A and Benedikt J 2012 Unexpected O and O 3 production in the effluent of $\mathrm{He} / \mathrm{O} 2$ microplasma jets emanating into ambient air Plasma Sources Sci. Technol. 21034019 
[33] Pintassilgo C D, Loureiro J and Guerra V 2005 Modelling of a N 2 -O 2 flowing afterglow for plasma sterilization J. Phys. D. Appl. Phys. 38 417-30

[34] Ricard A, Besner A, Hubert J and Moisan M 1988 High nitrogen atom yield downstream of an atmospheric pressure flowing Ar-N2 microwave discharge J. Phys. B At. Mol. Opt. Phys. 21 L579-83

[35] Tsyganov D and Pancheshnyi S 2012 Simulation of N-atom production in dielectricbarrier discharge in nitrogen at atmospheric pressure Plasma Sources Sci. Technol. 21 065010

[36] Choi J H, Han M H and Baik H K 2008 Experimental Analysis of Reduced Electric Field during Time-Variable Pulsed Dielectric Barrier Discharge Jpn. J. Appl. Phys. 47 1071-5

[37] Balcon N, Hagelaar G and Boeuf J-P 2008 Numerical Model of an Argon Atmospheric Pressure RF Discharge IEEE Trans. Plasma Sci. 36 2782-7

[38] Eliasson B, Hirth M and Kogelschatz U 1987 Ozone synthesis from oxygen in dielectric barrier discharges J. Phys. D. Appl. Phys. 20 1421-37

[39] Brehmer F K 2014 Shining Light on Transient CO2 Plasma (Eindhoven University of Technology)

[40] Fromy P, Pointu A-M, Ganciu M and Orphal J 2006 Transportation of nitrogen atoms in an atmospheric pressure post-discharge of pure nitrogen J. Phys. D. Appl. Phys. 39 $108-12$

[41] Penetrante B M 2002 NOx reduction by electron beam-produced nitrogen atom injection Patent 6345497

[42] Babayan S E, Ding G, Nowling G R, Yang X and Hicks R F 2002 Characterization of the Active Species in the Afterglow of a Nitrogen and Helium Atmospheric-Pressure Plasma Plasma Chem. Plasma Process. 22 255-69 

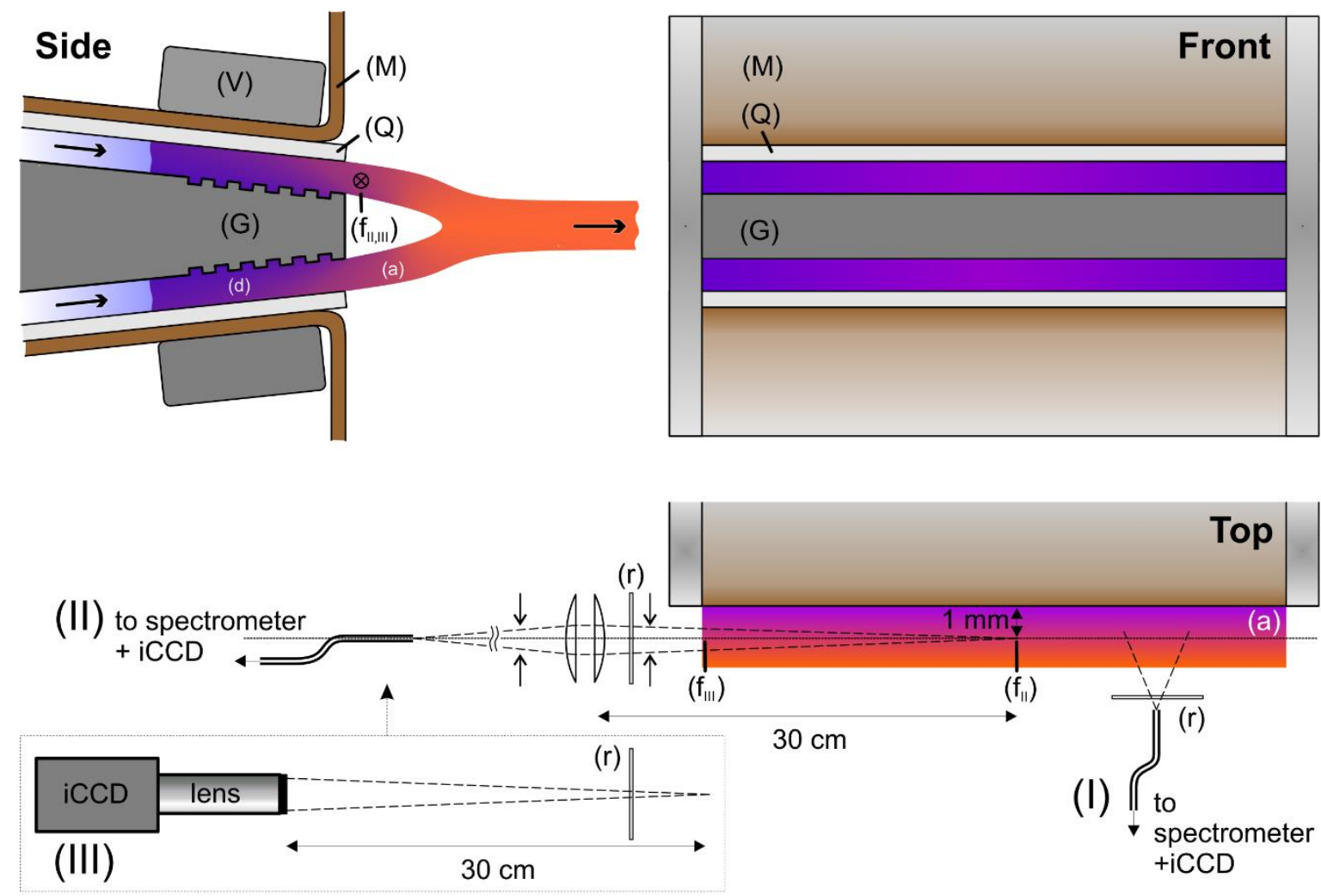

Figure 1: Schematic (cross-sectional) side, front and top view of the PlasmaLine source. Indicated are high voltage electrodes $(V)$, mica dielectric barriers $(M)$, quartz dielectric barriers $(\mathrm{Q})$, grounded central electrode $(\mathrm{G})$, discharge region (d), afterglow/jet region (a), optical filters (r) and focal points of optical setups (II) and (III) ( $\mathrm{f}_{\mathrm{II}, \mathrm{III}}$. Optical setup (I) is used to obtain the spectrum of the discharge, (II) to obtain the spectrum of the jet and (III) to image the FPS emission as a function of position.

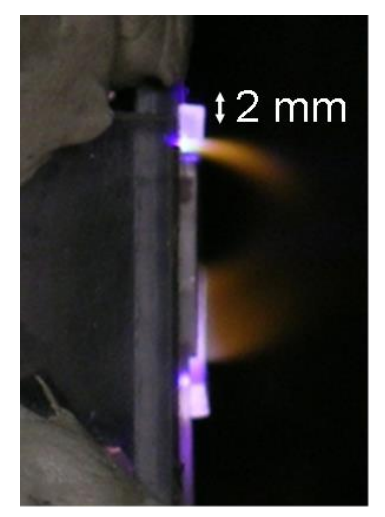

Figure 2: Photograph of the PlasmaLine ${ }^{\circledR}$ jets viewed from the side, with an indication of scale. 


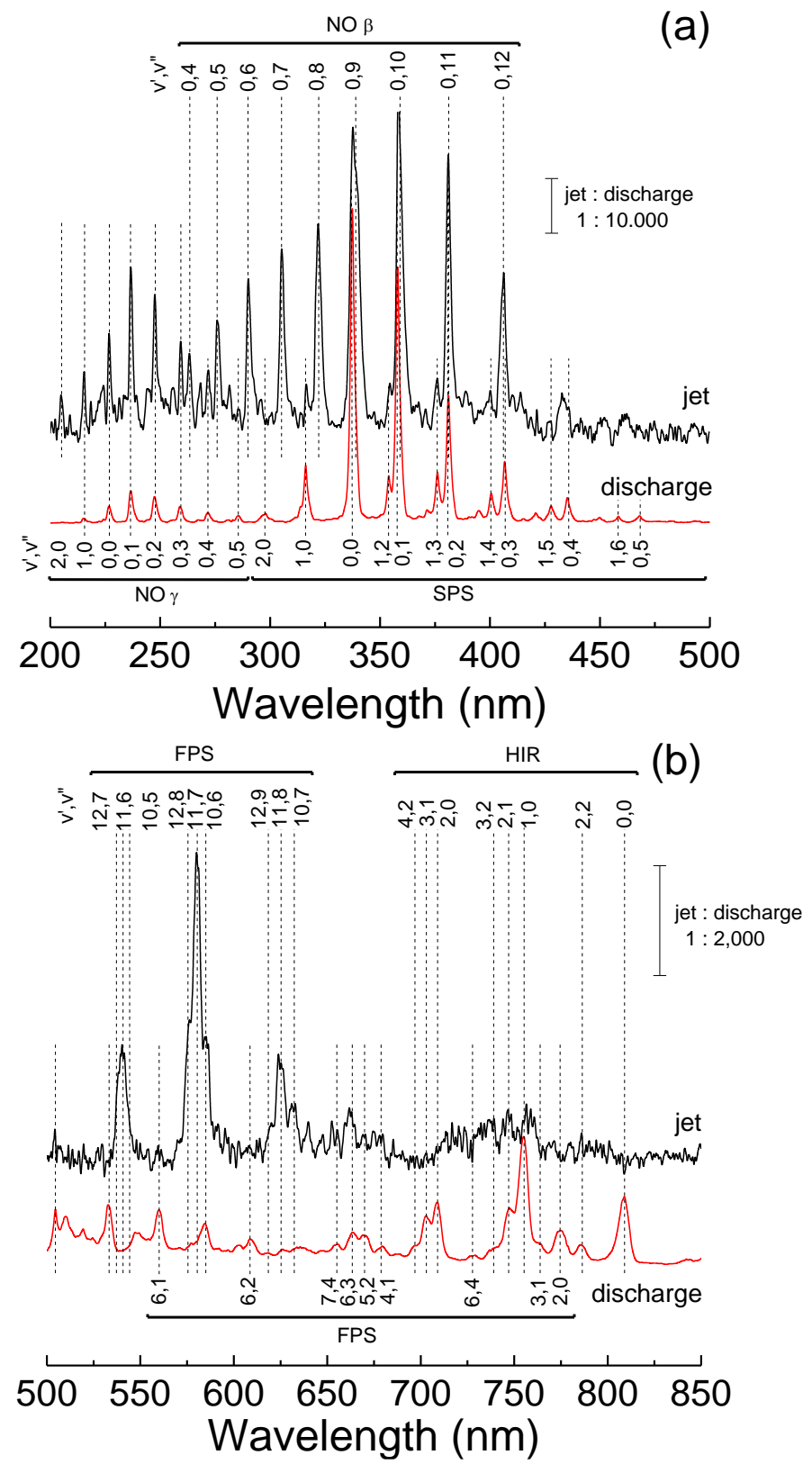

Figure 3: Optical emission spectra of the DBD discharge and jet at an applied voltage amplitude of $11.6 \mathrm{kV}$, (a) between $200-500 \mathrm{~nm}$ and (b) between $400-850 \mathrm{~nm}$. The relative vertical scales between the different plasma regions is indicated in each figure. 


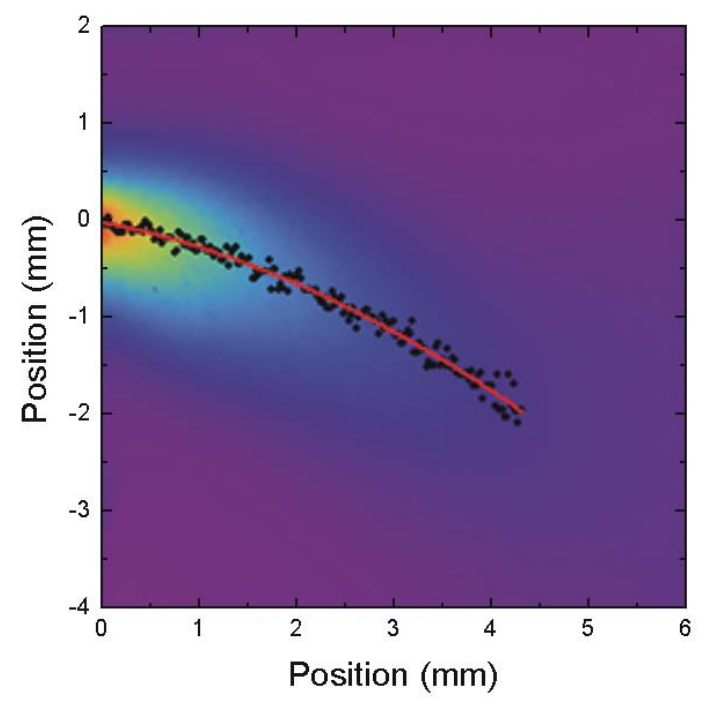

Figure 4: iCCD image of the FPS emission intensity of the atmospheric plasma jet operated with a gas flow of $200 \mathrm{slm}$ and an applied voltage amplitude of $11.6 \mathrm{kV}$. Black dots indicate the maximum value in each vertical column of pixels and the red line indicates a polynomial fit of these points, which consequently provides the trajectory of the gas flow.

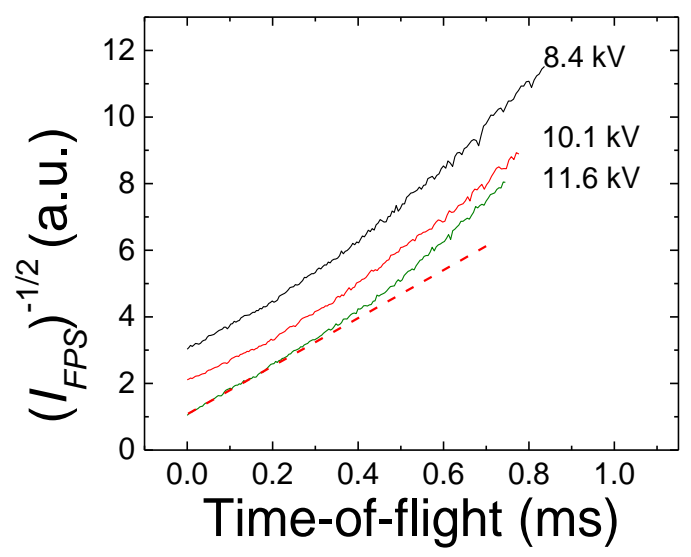

Figure 5: Inverse square root of the FPS emission intensity as a function of time-of-flight on the center streamline of the jet at a flow rate of $200 \mathrm{slm}$. The data sets are translated on the vertical axis for clarity. The dashed line is a linear fit of the $11.6 \mathrm{kV}$ data between 0 and $0.18 \mathrm{~ms}$. The upward deviation of the data with respect to the initial linearity is due to increased loss of $\mathrm{N}$ atoms through reactions with oxygen-containing species. 


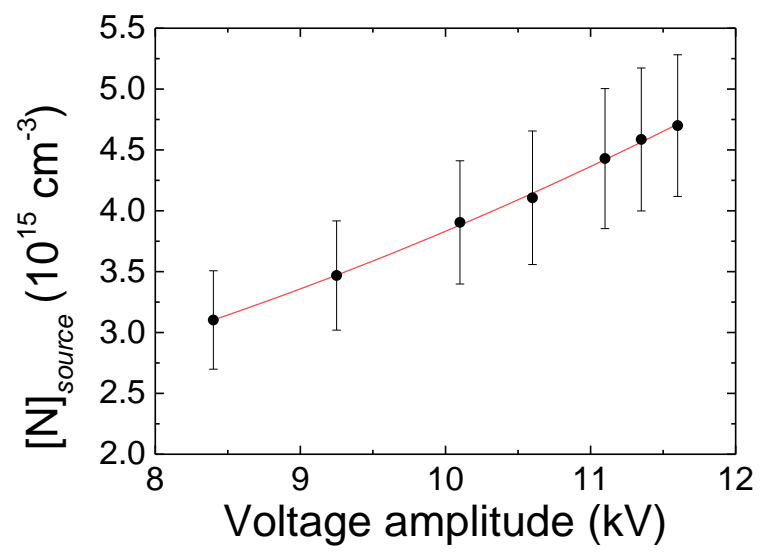

Figure 6: Atomic nitrogen concentration at the source exit $[\mathrm{N}]_{\text {source }}$ as a function of applied voltage amplitude in the DBD. The line is a guide to the eye.

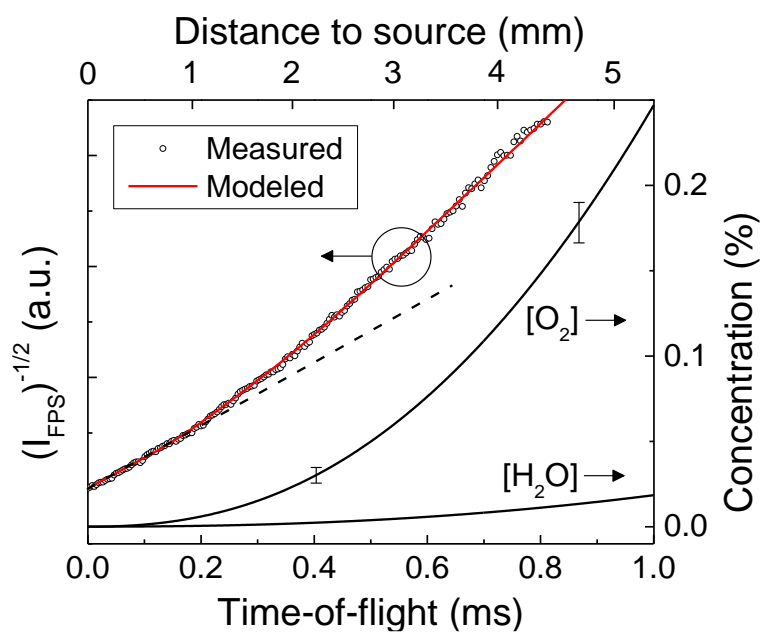

Figure 7: Fit of $\left[\mathrm{N}_{2}(\mathrm{~B})\right]^{-1 / 2}$ to $\left(\mathrm{I}_{\mathrm{FPS}}\right)^{-1 / 2}$ at an applied voltage amplitude of $10.1 \mathrm{kV}$ using the $1 \mathrm{D}$ convection-reaction model (left ordinate) and the increasing admixture of $\left[\mathrm{O}_{2}\right]$ and $\left[\mathrm{H}_{2} \mathrm{O}\right]$ in the plasma jet leading to this fit (right ordinate). The $3 \mathrm{ppm}\left[\mathrm{O}_{2}\right]$ and $2 \mathrm{ppm}\left[\mathrm{H}_{2} \mathrm{O}\right]$ contamination of the process gas is also taken into account. The fitted atomic $\mathrm{N}$ from the source, $[\mathrm{N}]_{\text {source, }}$, is $3 \%$ lower than expected from (4). 


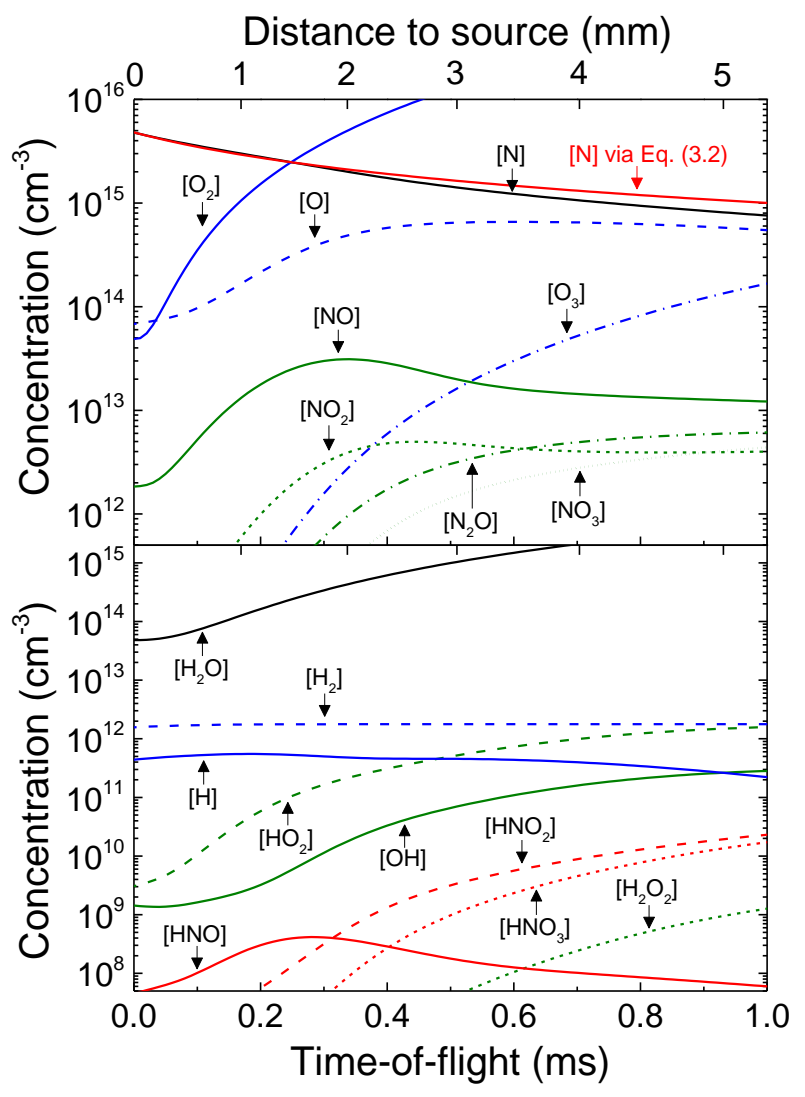

Figure 8: Calculated ground state species concentrations in the jet using the 380-reaction model, with $\mathrm{O}_{2}$ admixture from the surrounding air according to the fit in Figure 7. The red line near $[\mathrm{N}]$ indicates the atomic $\mathrm{N}$ concentration as it would be following (2) from the main text, in the absence of $\mathrm{O}_{2}, \mathrm{H}_{2} \mathrm{O}$ and $\mathrm{N}_{2}(\mathrm{~A})$.

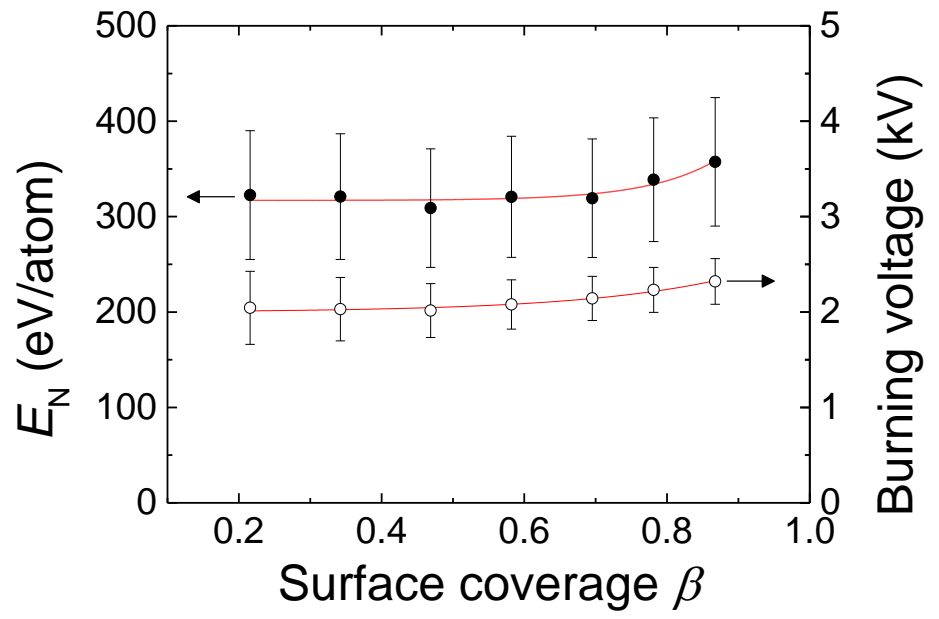

Figure 9: The atomic $N$ production efficiency $E_{N}$ and the burning voltage of the discharge $U_{b}$ as a function of surface coverage $\beta$. The surface coverage depends only on the applied voltage amplitude of the DBD. The lines are guides to the eye. 
Table 1: Species considered in the 1D chemical kinetic model. The top rows show all species for which a nonzero initial value is used at $\mathrm{t}=-0.2 \mathrm{~ms}$ from the source exit.

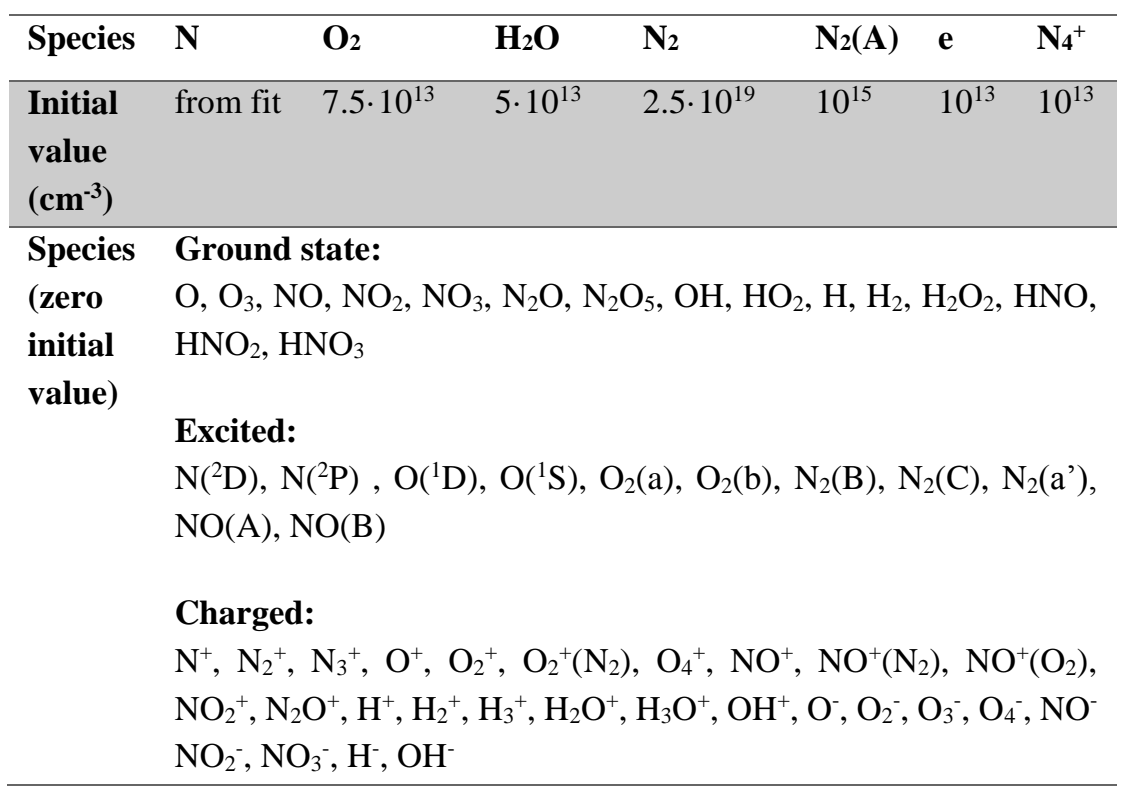

Table 2: Comparison of maximum atomic $\mathrm{N}$ concentrations from various plasma sources operated at atmospheric pressure. The energy input per $\mathrm{N}$ atom from the source $\mathrm{E}_{\mathrm{N}}$ is given in $\mathrm{eV} /$ atom. It is assumed that the surface coverage $\beta=1$ in all cases, though this is only certain for the results obtained in this work.

\begin{tabular}{|c|c|c|c|c|c|c|c|}
\hline $\begin{array}{l}\text { Source } \\
\text { type }\end{array}$ & Gas & $\begin{array}{l}{[\mathbf{N}]_{\text {source }}} \\
\left(\mathbf{1 0}^{15}\right. \\
\left.\mathbf{c m}^{-3}\right)\end{array}$ & Method & $\begin{array}{l}P \\
(\mathbf{W})\end{array}$ & $\begin{array}{l}\Phi \\
(\operatorname{slm})\end{array}$ & $\begin{array}{l}\boldsymbol{E}_{N} \\
\text { (eV/atom) }\end{array}$ & Ref. \\
\hline DBD & $\mathrm{N}_{2}$ & 4.5 & Emission & 500 & 200 & 320 & $\begin{array}{l}\text { This } \\
\text { work }\end{array}$ \\
\hline DBD & $\mathrm{N}_{2}$ & 1.0 & $\begin{array}{l}\mathrm{NO} \\
\text { titration }\end{array}$ & 60 & 68 & 360 & {$[1,2]$} \\
\hline $\begin{array}{l}\text { DBD } \\
\text { (Townsend) }\end{array}$ & $\mathrm{N}_{2}$ & $\leq 0.3$ & TALIF & 1.5 & variable & 830 & [18] \\
\hline $\begin{array}{l}\text { DBD } \\
\text { (Filamentary) }\end{array}$ & $\mathrm{N}_{2}$ & $\leq 0.3$ & TALIF & 1.6 & variable & 300 & [18] \\
\hline Corona & $\mathrm{N}_{2}$ & 0.5 & $\begin{array}{l}\mathrm{NO} \\
\text { titration }\end{array}$ & 15 & 45 & 280 & {$[4,40]$} \\
\hline $\begin{array}{l}\text { Electron } \\
\text { beam }\end{array}$ & $\mathrm{N}_{2}$ & 2.7 & $\begin{array}{l}\mathrm{NO} \\
\text { titration }\end{array}$ & 600 & 2 & 420 & [41] \\
\hline Microwave & $\begin{array}{l}\mathrm{Ar}, \\
0.3 \% \\
\mathrm{~N}_{2}\end{array}$ & 17 & $\begin{array}{l}\mathrm{NO} \\
\text { titration }\end{array}$ & 200 & 10 & 440 & [34] \\
\hline $\begin{array}{l}\text { Arc } \\
\text { discharge }\end{array}$ & $\begin{array}{l}\mathrm{He}, \\
1.3 \% \\
\mathrm{~N}_{2}\end{array}$ & 4.8 & $\begin{array}{l}\text { Calibrated } \\
\text { emission }\end{array}$ & 200 & 30 & 510 & [42] \\
\hline
\end{tabular}

